\title{
REVIEW ON LATENT HEAT STORAGE AND PROBLEMS ASSOCIATED WITH PHASE CHANGE MATERIALS.
}

\author{
Kavendra A. Thakare ${ }^{1}$, A. G. Bhave ${ }^{2}$

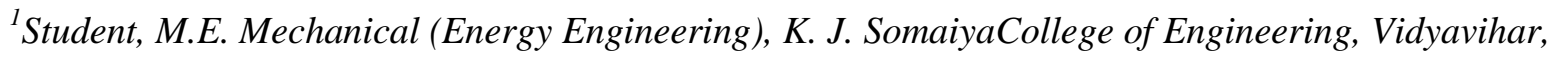 \\ Mumbai-400077, India. \\ ${ }^{2}$ Senior Professor, Department ofMechanical engineering, K. J. SomaiyaCollege of Engineering, Vidyavihar, \\ Mumbai-400077, India.
}

\begin{abstract}
Energy storage devices have important role in the energy system as they minimize the mismatch between the supply and demand. This leads to improvement of the performance and the reliability of the systems. In thermal energy storage systems the Latent heat type thermal energy storages (LHTES) are attractive since they have high energy storage density and nearly isothermal operation at the phase transition temperature of the material usedthat is commonly known as phase change material (PCM). In this paper PCMs with solid-solid and solid-liquid phase transition are discussed. Though PCMs with solid-solid phase transition seem attractive due to their less stringent containment requirements but they are not widely used because of their low latent heat. PCMs with solid-liquid phase transition are the most studied and used latent heat storage materials. Those are discussed in details with their selection criterion, classification and applications. The steps involved in development of the energy storage systems and problems associated with PCMs are discussed in the next part of the paper. This will give better understanding of the latent heat storage systems to the reader.
\end{abstract}

KeyWords: Latent heat storage (LHS), Phase change materials (PCM), Thermal conductivity, Thermal cycling.

\section{INTRODUCTION}

In energy systems, energy storages have crucial role to play as to ensure the supply on demand, to improve the performance and reliability and to conserve energy $[1,2]$.There are various types of energy storages viz. (i) Mechanical Energy Storage e.g. flywheel etc., (ii) Electrical Energy storage e.g. battery etc. and (iii) Thermal Energy Storage e.g. sensible heat, latent heat and thermochemical storages.

In Sensible heat storages,thermal energy is stored on an account of temperature difference. Quantity of thermal energy storage depends upon, temperature gradient, specific heat capacity of medium and amount of storage material used,

$$
Q=m C_{p} \Delta T=m C_{p}\left(T_{f}-T_{i}\right)
$$

e.g. water, pebble bed, thermic oils etc.

In Latent heat storages (LHS), thermal energy is stored on the account of heat absorbed or released during phase changeof the storage material.The storage capacity of the LHS with solid to liquid phase change is given as,

$$
Q=m\left[C_{p s}\left(T_{m}-T_{i}\right)+a_{m} H_{L}+C_{p l}\left(T_{f}-T_{m}\right)\right]
$$

e.g. Paraffins, salt hydrates etc.

In Thermochemical storage, thermal energy is stored in the form of the heat of the reaction of the completely reversible chemical reaction. The amount of heat stored depends upon amount of storage material, the endothermic heat of reaction and the extent of reaction.
\[ =m f_{r} H_{R} \]
e.g. $\mathrm{CH}_{4}+\mathrm{H}_{2} \mathrm{O} \leftrightarrow \mathrm{CO}+3 \mathrm{H}_{2}$ etc.

\section{1latent Heat Storage}

Latent heat storages are the thermal energy storages in which storage material undergoes change of phase and thermal energy is stored in the form of the latent heat of phase change of the corresponding material. Principle of latent heat storageis as shown in Fig-1.

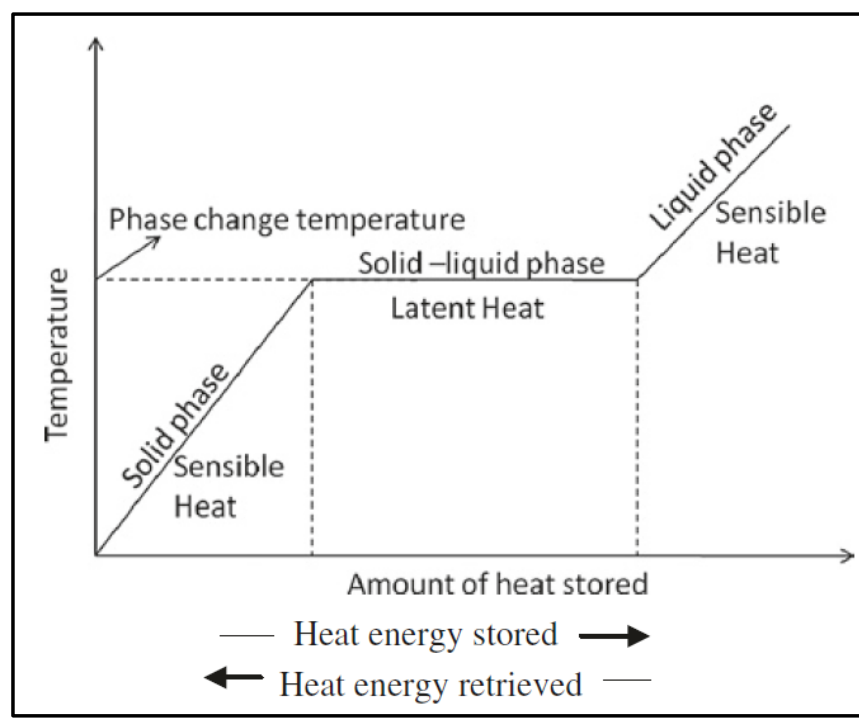

Fig-1: Principle of latent heat storage. 
The material used in latent heat storage is called as Phase Change Material (PCM) since it undergoes change ofphase. Latent heat storages have some advantages over sensible heat storages. i.e.

- High storage density,

- Roughly isothermal operation near phase change temperature of the PCM.

The Fig-2 gives the comparison between sensible and latent type heat storages [3].

\begin{tabular}{|lllll|}
\hline Property & Rock & Water & Organic PCM & Inorganic PCM \\
\hline Density, $\mathrm{kg} / \mathrm{m}^{3}$ & 2240 & 1000 & 800 & 1600 \\
Specific heat, $\mathrm{kJ} / \mathrm{kg}$ & 1.0 & 4.2 & 2.0 & 2.0 \\
Latent heat, $\mathrm{kJ} / \mathrm{kg}$ & - & - & 190 & 230 \\
Latent heat, $\mathrm{kJ} / \mathrm{m}^{3}$ & - & - & 152 & 368 \\
Storage mass for $10^{6} \mathrm{~J}, \mathrm{~kg}$ & 67,000 & 16,000 & 5300 & 4350 \\
Storage volume for $10^{6} \mathrm{~J}, \mathrm{~m}^{3}$ & 30 & 16 & 6.6 & 2.7 \\
Relative storage mass & 15 & 4 & 1.25 & 1.0 \\
Relative storage volume & 11 & 6 & 2.5 & 1.0 \\
\hline
\end{tabular}

Fig-2: Comparison of Sensible and Latent heat storages.

The possible combinations of change of phase may be of solid-solid, solid-liquid, solid-gas and liquid-gas or viceversa. Amongst them solid-gas and liquid-gas have high latent heat of phase change but have containment problems because of their high volume changes. This makes them non-suitable for practical implementation in thermal storages.

In Solid-solid phase transitions, heat is stored in the material as its crystal structure changes from one to other [4-6].

In Solid-liquid phase transitions, the volume changes are comparatively low (around 10\%). This type of PCMs are widely studied and used.

Following Table-1 gives comparison between Solid-solid and Solid-liquid PCMs.

Table-1: Comparison of Solid-solid and Solid-liquid PCMs.

\begin{tabular}{|l|l|l|}
\hline & Solid-solid & Solid-liquid \\
\hline Heat stored due to & $\begin{array}{l}\text { Change in crystal } \\
\text { structure }\end{array}$ & $\begin{array}{l}\text { Change in } \\
\text { Phase }\end{array}$ \\
\hline Volume changes & Very small & Small \\
\hline Storage density & Comparatively low & Higher \\
\hline Containment & Less stringent & More stringent \\
\hline Encapsulation & Not needed & Needed \\
\hline Design flexibility & Greater & Moderate \\
\hline Cost & High & $\begin{array}{l}\text { Comparatively } \\
\text { low }\end{array}$ \\
\hline Availability & Not easily available & $\begin{array}{l}\text { Easily } \\
\text { available }\end{array}$ \\
\hline
\end{tabular}

Some examples of solid-solid PCMs from available literature are listed in Table-2 [5, 6].
Table-2: List ofSolid-solid type PCMs.

\begin{tabular}{|l|l|l|}
\hline PCM & $\begin{array}{l}\text { Phase } \\
\text { transition } \\
\text { temperature } \\
\left({ }^{\circ} \mathbf{C}\right)\end{array}$ & $\begin{array}{l}\text { Latent } \\
\text { heat } \\
(\mathbf{k J} / \mathbf{k g . K})\end{array}$ \\
\hline Neopentyl Glycol (NPG) & 43 & 130 \\
\hline Crosslinked Polyethylene & $110-115$ & $125-146$ \\
\hline Cross linked HDPE & $125-146$ & $167-201$ \\
\hline $38.2 \%$ NPG / 61.8\% PE & 170 & 147 \\
\hline Pentaerithrytol (PE) & 180 & 303 \\
\hline
\end{tabular}

\subsection{Desirable Properties Of Phase Change}

\section{Materials}

- $\quad$ Selection criterion for the PCM is given below [1,7].

- $\quad$ Phase change temperature of the PCM must be suitable for required thermal application.

- $\quad$ PCM should possess high heat of fusion per unit weight and volume, so that small amount of material can hold large magnitudes of thermal energy.

- High specific heat enables the PCM to store more sensible heat.

- $\quad$ PCM should have high thermal conductivity in both the phases which enables storing and extraction of thermal energy from the storage with less temperature gradient.

- $\quad$ PCM should have high density, so that the container required for storage would be small and of low cost.

- $\quad$ PCM should possess low vapor pressure; this gives mechanical stability to PCM containers.

- Volume change during phase transition should be low, so that simple container and heat exchanger can be used.

- $\quad$ PCM should completely melt, i.e., congruent melting, so that segregation can be avoided and homogeneous solid and liquid phases can be obtained.

- $\quad$ PCM should show little or no super-cooling with high rate of crystal growth; this enables melting and solidification to occur at same temperature.

- PCM operation should be reliable without any degradation for long time.

- $\quad$ PCM should possess completely reversible melting and solidification cycle.

- $\quad$ PCM should be chemically stable and non-poisonous.

- PCM should not corrode the container and heat exchanger materials.

- $\quad$ PCM should be non-hazardous and inflammable.

- $\quad$ PCM should be inexpensive, easily available and long lasting.

- As no single PCM satisfies the all criterion stated above, so PCM with more suitable properties should be selected. 


\section{CLASSIFICATION OF SOLID-LIQUID} PHASE CHANGE MATERIALS

Solid-liquid PCMs are classified into three categories named Organic compounds, Inorganic compounds and Eutectics. Detail classification is given in the Fig-3 $[1,4]$.

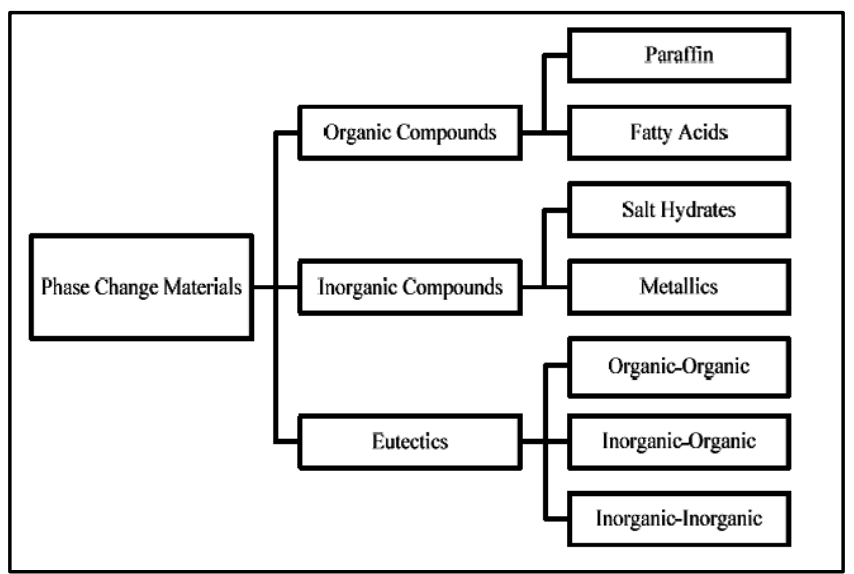

Fig-3: Types of Solid-Liquid Phase Change Materials.

\subsection{Organic Compounds}

These are organic materials and further sub-categorised as paraffins and non-paraffins.

\section{(a) Paraffins:}

These are mostly straight chain alkanes.Their melting point and latent heat increase with increase in chain length.

Advantages: Availability in large temperature range.

Congruent melting and good nucleating properties.

Reliable and predictable behavior.

Safe and non- corrosive.

Economic.

Disadvantages: Low thermal conductivity.

Non compatibility with plastic containers.

Moderately flammable.

\section{(b) Non-paraffins:}

These are most numerous PCMs with varied properties.Most of them are esters, fatty acids, alcohols and glycols with high heat of fusion.

Advantages: High heat of fusion, Inflammable.

Disadvantages: Low thermal conductivity, low flashpoint.

Instability at higher temperature.

High cost.

\subsection{Inorganic Compound}

Inorganic PCMs are further categorized as salt hydrates and metallics. These PCMs do not show appreciable supercooling and show favorable thermal cycling.

\section{(a) Salt hydrates:}

These are nothing but the alloys of inorganic salt and water, in which crystalline solids are formed.Solid-liquid phase transition of salt hydrates is the process of hydration and dehydration.

Advantages: High latent heat of fusion per unit volume.
Relatively high thermal conductivity. Small volume changes on melting. Inexpensive.

Disadvantages: Phase separation, poor nucleation properties and incongruent melting.

\section{(b)Metallics:}

These are the low melting metals and metal eutectics.

Advantages: High thermal conductivity.

High heat of fusion per unit volume.

Low vapour pressure.

Disadvantages: Higher weight.

\subsection{Eutectics}

Eutectic is a mixture of two or more components with minimum melting point called as eutectic point, in which each component melts and freezes congruently forming mixture of crystals of components. Eutectics aresub-divided into organic-organic, inorganic-inorganic andorganicinorganic types.

Fig-4shows chart of comparison of different types of PCM.

\begin{tabular}{|lll|}
\hline Classification & Advantages & Disadvantages \\
\hline Organic PCMs & 1. Availability in a large temperature range & 1. Low thermal conductivity \\
& 2. High heat of fusion & 2. Relative large volume \\
& 3. No supercooling, & change \\
& 4. Chemically stable and recyclable & 3.Flammability \\
5. Good compatibility with other materials & \\
Inorganic PCMs & 1. High heat of fusion & 1. Supercooling \\
& 2. High thermal conductivity & 2. Corrosion \\
3. Low volume change & \\
4. Availability in low cost & 1. Sharp melting temperature & Lack of currently available \\
2. High volumetric thermal storage density & test data of thermo-physical \\
& & properties \\
\hline
\end{tabular}

Fig-4:Comparison of all types of PCM.

Table-3 gives list of PCMs from each category[1,5,6]. 
Table-3: List of Phase change materials.

\begin{tabular}{|c|c|c|c|}
\hline Type & Material & $\begin{array}{l}\text { M.P. } \\
\left({ }^{\circ} \mathbf{C}\right)\end{array}$ & $\begin{array}{l}\text { Latent } \\
\text { heat of } \\
\text { fusion } \\
(\mathrm{kJ} / \mathrm{kg})\end{array}$ \\
\hline \multirow[t]{6}{*}{ Paraffins } & $\begin{array}{l}\text { (Carbon atom no. } \\
\text { in alkane) }-14\end{array}$ & 5.5 & 228 \\
\hline & 15 & 10 & 205 \\
\hline & 16 & 16.7 & 237.1 \\
\hline & 17 & 21.7 & 213 \\
\hline & 18 & 28 & 244 \\
\hline & 19 & 32 & 222 \\
\hline \multirow[t]{10}{*}{ Non-paraffins } & Bees wax & 61.8 & 177 \\
\hline & Alpha napthol & 96 & 163 \\
\hline & Quinone & 115 & 117 \\
\hline & Acetanilide & 118.9 & 222 \\
\hline & $\begin{array}{l}\text { Succinic } \\
\text { anhydride }\end{array}$ & 119 & 204 \\
\hline & Benzoic acid & 121.7 & 142.8 \\
\hline & Stilbene & 124 & 167 \\
\hline & Benzamide & 127.2 & 169.4 \\
\hline & Phenacetin & 137 & 136.7 \\
\hline & Alpha glucose & 141 & 174 \\
\hline \multirow[t]{6}{*}{ Fatty acids } & Acetic acid & 16.7 & 184 \\
\hline & $\begin{array}{l}\text { Polyethylene } \\
\text { glycol } 600\end{array}$ & $20-25$ & 146 \\
\hline & Lauric acid & 49 & 178 \\
\hline & Myristic acid & 58 & 199 \\
\hline & Stearic acid & 69 & 202.5 \\
\hline & Acetamide & 81 & 241 \\
\hline \multirow[t]{7}{*}{ Salt hydrates } & $\mathrm{Al}\left(\mathrm{NO}_{3}\right)_{2} \cdot 9 \mathrm{H}_{2} \mathrm{O}$ & 72 & 155 \\
\hline & $\mathrm{Ba}(\mathrm{OH})_{2} .8 \mathrm{H}_{2} \mathrm{O}$ & 78 & 265 \\
\hline & $\mathrm{Mg}\left(\mathrm{NO}_{3}\right)_{2} \cdot 6 \mathrm{H}_{2} \mathrm{O}$ & 89.9 & 167 \\
\hline & $\mathrm{KAl}\left(\mathrm{SO}_{4}\right)_{2} \cdot 12 \mathrm{H}_{2} \mathrm{O}$ & 91 & 184 \\
\hline & $\mathrm{LiCl} . \mathrm{H}_{2} \mathrm{O}$ & 99 & 212 \\
\hline & $\mathrm{MgCl}_{2} \cdot 6 \mathrm{H}_{2} \mathrm{O}$ & 117 & 167 \\
\hline & $\mathrm{NaC}_{2} \mathrm{H}_{3} \mathrm{O}_{2} .3 \mathrm{H}_{2} \mathrm{O}$ & 137 & 172 \\
\hline \multirow[t]{5}{*}{ Metallics } & Gallium & 30 & 80.1 \\
\hline & Cerrolow eutectic & 58 & 90.9 \\
\hline & Bi-Cd-In eutectic & 61 & 25 \\
\hline & Bi-Pb-In eutectic & 70 & 29 \\
\hline & Bi-In eutectic & 72 & 25 \\
\hline \multirow[t]{5}{*}{ Eutectic } & $\begin{array}{l}\text { Tryethylolethane } \\
67.5 \% \text { + Urea } 32.5 \%\end{array}$ & 29.8 & 218 \\
\hline & $\begin{array}{l}\mathrm{Mg}\left(\mathrm{NO}_{3}\right)_{2} \cdot 6 \mathrm{H}_{2} \mathrm{O} 50 \% \\
+\mathrm{MgCl}_{2} \cdot 6 \mathrm{H}_{2} \mathrm{O} 50 \%\end{array}$ & 59.1 & 144 \\
\hline & $\begin{array}{l}\mathrm{Mg}\left(\mathrm{NO}_{3}\right)_{2} \cdot 6 \mathrm{H}_{2} \mathrm{O} 53 \% \\
+\mathrm{Al}\left(\mathrm{NO}_{3}\right)_{2} \cdot 9 \mathrm{H}_{2} \mathrm{O} 47 \%\end{array}$ & 61 & 148 \\
\hline & $\begin{array}{l}\text { Napthalene } 67.1 \%+ \\
\text { Benzoic acid } 32.9 \%\end{array}$ & 67 & 123.4 \\
\hline & $\begin{array}{l}\mathrm{LiNO}_{3} 27 \%+ \\
\mathrm{NH}_{4} \mathrm{NO}_{3} 68 \%+ \\
\mathrm{NH}_{4} \mathrm{Cl} 5 \%\end{array}$ & 81.6 & 108 \\
\hline
\end{tabular}

\section{LATENT HEAT STORAGE SYSTEMS}

\subsection{Design Of Latent Heat Storage Systems}

Design of storage system involves three steps [8]:

1. Selection of suitable storage material i.e. PCM.

2. Design of containment for storage material.

3. Heat exchanger for charging and discharging.

Steps involved in development of latent heat thermal storage systems are categorized in three parts as

1. Selection of PCM and optimization of its properties.

2. Designing of heat exchanger for charging and discharging.

3. Performance evaluation on technical and economic aspects.

Then the system is optimized for commercialization. Therefore it important to analyse the system numerically and experimentally [1,9]. These steps are shown schematically in Fig-5.

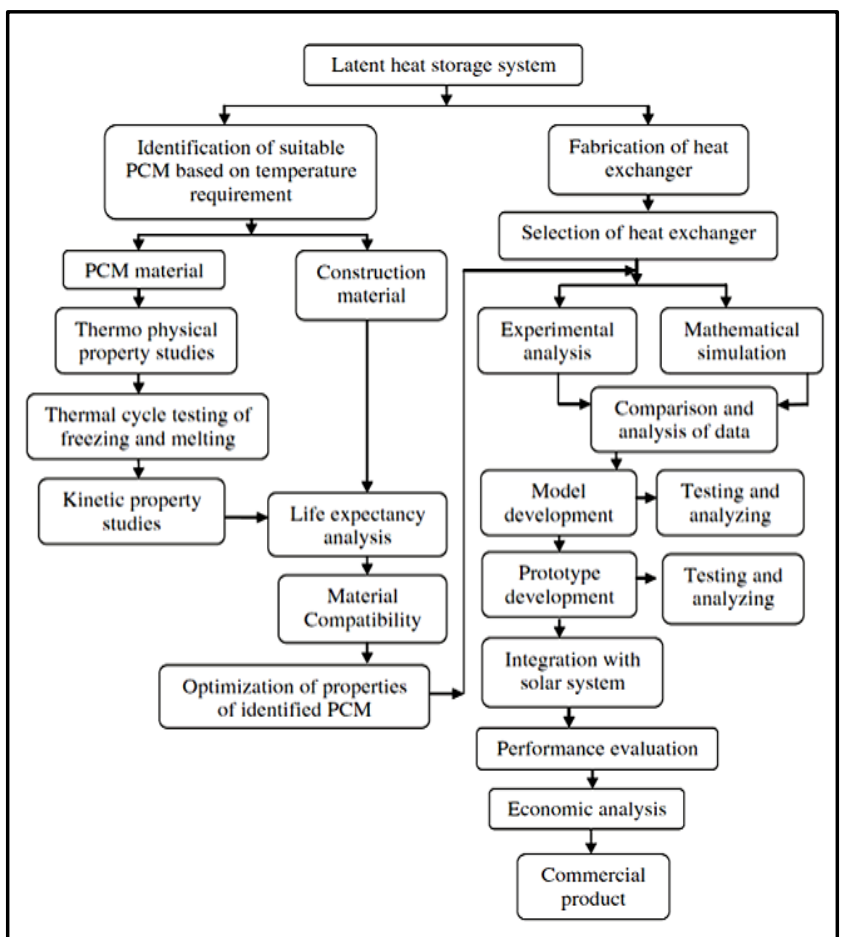

Fig-5:Steps involved in development of latent heat thermal storage systems.

\subsection{Applications Of LHTES}

There are numerous applications of latent heat storages in various fields. Some of them are stated below $[10,11]$.

- Thermal storage of solar energy

- Passive storage in bioclimatic building/architecture

- Cooling: use of off-peak rates and reduction of installed power, ice-bank.

- Heating and sanitary hot water: using off-peak rate and adapting unloading curves.

- Safety: temperature maintenance in rooms with computers or electrical appliances.

- Thermal protection of food: transport, hotel trade, icecream, etc.

- Food agroindustry, wine, milk products (absorbing 
peaks in demand), greenhouse.

- Thermal protection of electronic devices (integrated in the appliance)

- Medical applications: transport of blood, operating tables, hot-cold therapies.

- Cooling of engines (electric and combustion).

- Thermal comfort in vehicles.

- Softening of exothermic temperature peaks in chemical reactions.

- $\quad$ Spacecraft thermal systems

- Solar power plant, etc.

Cristopia (France), TEAP Energy (Australia), Rubitherm GmbH (Germany), EPS Ltd. (UK), PCM Thermal solutions (USA), Climator (Sweden) and Mitsubhishi Chemicals (Japan) etc. are the PCM manufacturer companies around the world [11].

Also PlusICEproduct range like TubeICE, FlatICE, BallICE, Eutectic plates and Pouches from Phase Change Material Products Ltd., UK [12], are available and being used in various applications mentioned above.

\section{PROBLEMS ASSOCIATED WITH PCMS}

Various problems are encountered during operation of thermal energy storages. These problems are listed below.Many researchers exploited these problems and given their recommendations to minimize or eliminate the same.

\subsection{Phase Separation.}

This kind of problem is observed in the inorganic PCMs i.e. salt hydrates. It occurs due to incongruent melting and density difference of inorganic salt and water. Remedies[1,7]over this are (i) Mechanical stirring, (ii) Encapsulation of PCM to reduce phase separation, (iii) Addition of thickening or gelling agent to suspend heavy phase in the solution, (iv) Extra-water Principle to avoid supersaturation of the solution, (v) Modification of chemical composition of system to make incongruent material congruent.

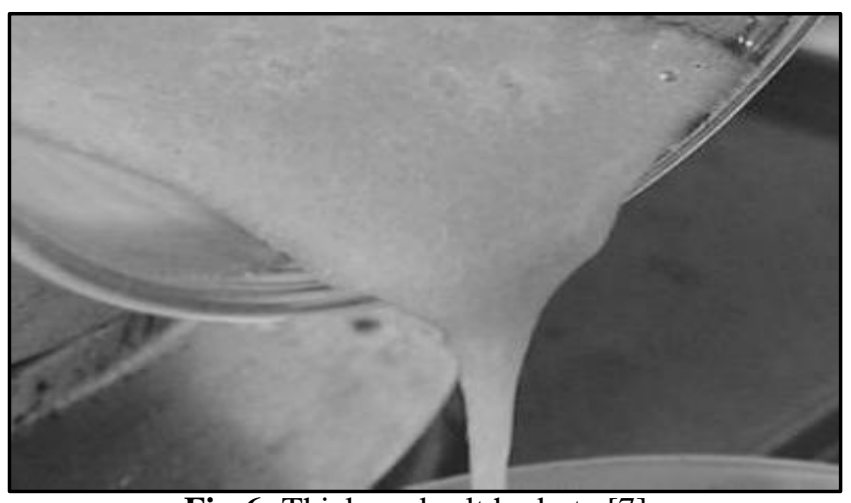

Fig-6: Thickened salt hydrate [7].

\subsection{Super-Cooling Or Sub-Cooling}

The difference between melting and solidification temperature of PCM is known as degree of super-cooling or sub-cooling. This generally occurs due to poor nucleation rate in the PCM. Because of super-cooling heat is discharged at the lower temperature than fusion temperature. This hampers the heat transfer rate and amount of heat retrieved. Sometimes super-cooling may result in no latent heat release.To avoid these circumstances the nucleation properties of the PCM should be increased by adding nucleating agents.List of some nucleating agents is given in Table-4 [6].

Table-4: List of nucleating agents.

\begin{tabular}{|l|l|}
\hline Nucleating agent & Size $(\mu \mathrm{m})$ \\
\hline Borox & $(20 \times 50-200 \times 250)$ \\
\hline Carbon & $(1.5-6.7)$ \\
\hline $\mathrm{TiO}_{2}$ & $(2-200)$ \\
\hline Copper & $(1.5-2.5)$ \\
\hline Aluminium & $(8.5-20)$ \\
\hline $\mathrm{Na}_{2} \mathrm{SO}_{4}$ & - \\
\hline
\end{tabular}

Fig-7 shows effect of supercooling (subcooling) on latent heat retrieval from LHS.

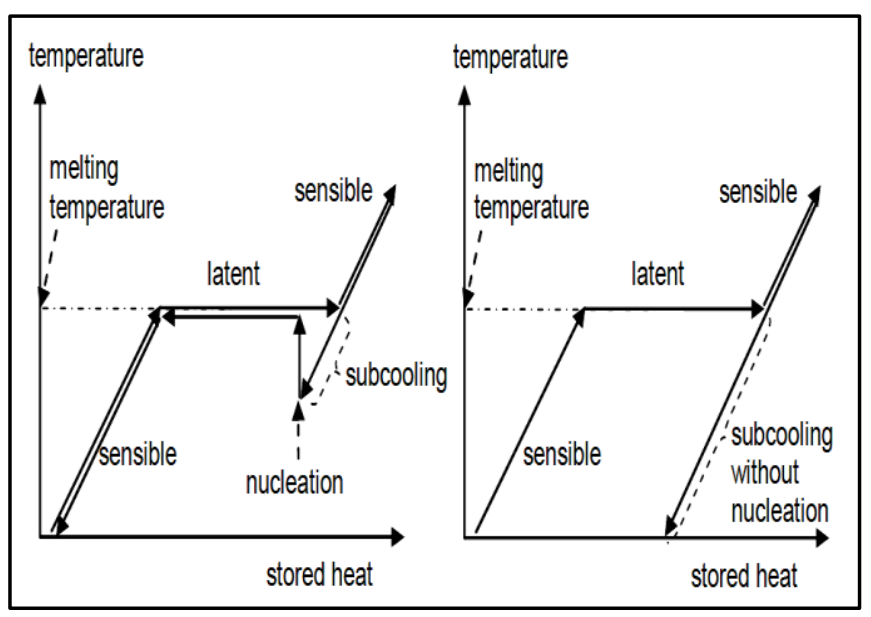

Fig-7: Effect of sub-cooling on heat storage. Left: with little sub-cooling and nucleation, right:severe sub-cooling without nucleation.

\subsection{Low Thermal Conductivity}

The major problem faced in latent heat storage systems is the slow heat transfer rate or response rate. This is mainly due to low thermal conductivity of the available PCMs. Thermal conductivity of the PCMs can be improved by adding high thermally conductive nanoparticles or adding fins or mesh of conductive and compatible material. Though this improves overall thermal conductivity of the storage medium but this adds cost and weight penalties resulting in less thermal storage density.

The experiments to improve the thermal conductivity showed the better performance of the system. Also these provides mechanical strength to the storage medium as well as to the system. Fig- 8 shows experimental investigations of various fin geometries used [13]. 


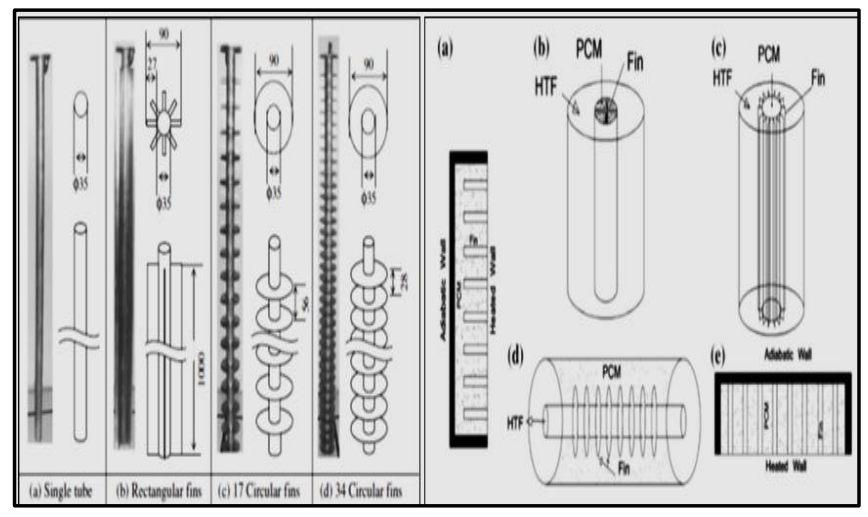

Fig-8: Various fin geometries used in LTES.

Also to improve thermal conductivity and mechanical stability, PCM can be combined with other material like graphite or metal foam to form a composite material.

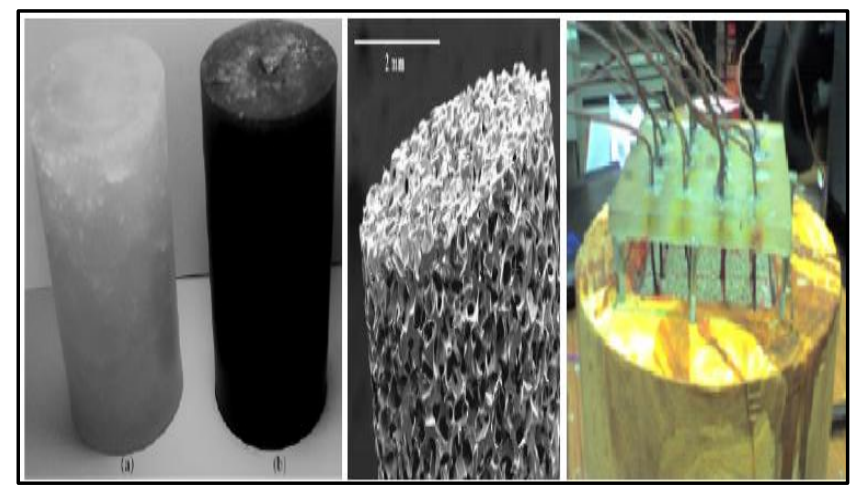

Fig-9: PCM composites: Left-(a) Pure paraffin (b) Paraffin /EG composite; Centre- Metal foam; Right: Metal foam embedded in wax [7] [14].

Recently to counteract the problem of low thermal conductivity, heat pipe heat exchangers were used in the LTES systems. Use of heat pipes shows better flexibility to the storage system. Fig-10 shows use of heat pipes in the heat transfer enhancement between HTF and PCM [15].

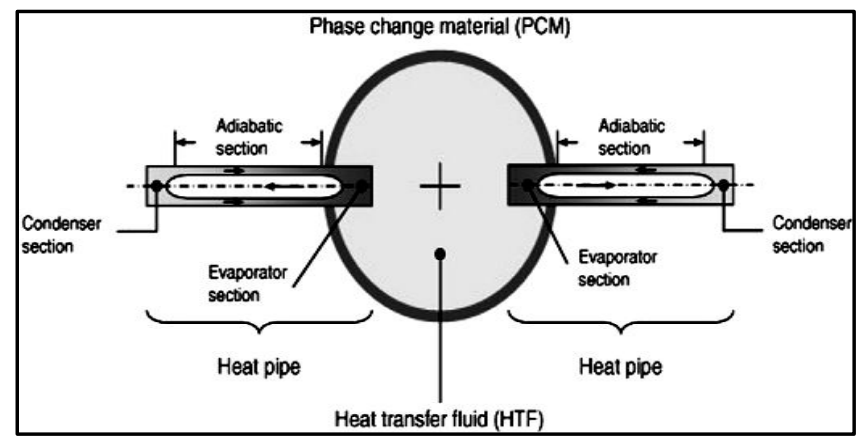

Fig-10: Heat transfer enhancement using heat pipes.

\subsection{Thermal Stability}

In order to achieve efficient heat transfer without degradation, to avoid leakage of the PCM and to avoid contact of PCM with external unsuitable environment, PCMs are encapsulated. Encapsulations are classified on account of their sizes into macro-encapsulation and micro- encapsulation. Micro-encapsulation results in increase in heat transfer area in same volume and also increase in thermal cycling of the PCM [7].

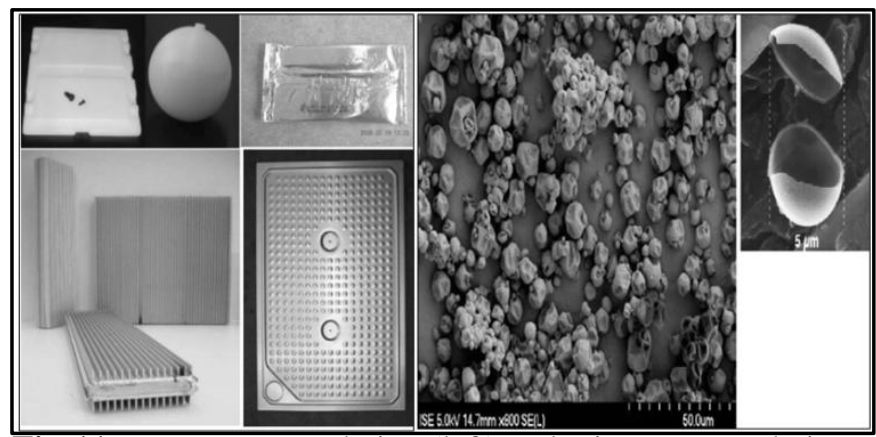

Fig-11: Macro-encapsulation (left) and micro-encapsulation (right).

\subsection{Corrosion}

Compatibility is most important aspect while designing LHTES. If material is not compatible with the container, then it will result in corrosion of the container also in some changes of PCM properties. The final result is poor performance of the system. It also results in waste of cost and effort invested. Thus before designing LHTES the compatibility of the PCM and containment material should be checked.

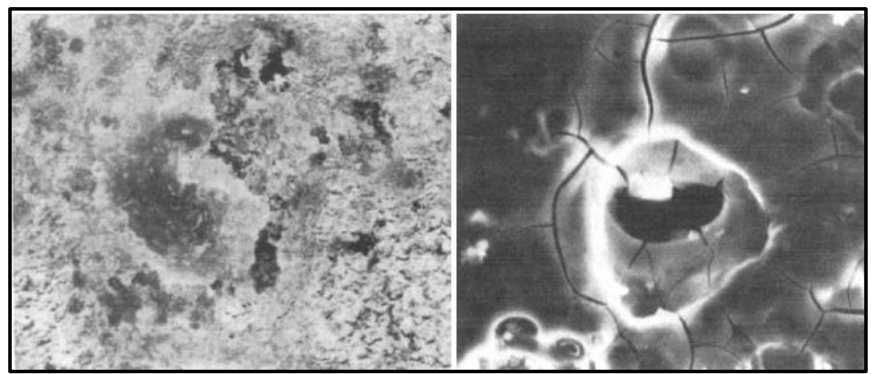

Fig-12: Corrosion: Left- Copper surface after 50 days contact with melt of sodium thiosulphate 5-hydrate; Right: SEM phorograph of $\mathrm{AlMg}_{3}$ after 80 days contact with melt of sodium hydrogen phosphate 12-hydrate.

\section{APPLICATION OF PCM INCONCENTRATING SOLAR POWER}

Important application LHS is in concentrating solar power (CSP) plants [4, 15]. Fig-13 shows schematic diagram of CSP plant withmolten salt -two tank thermal energy storage system with conventionalheat transfer fluid (HTF). During sunshine hours the surplus heat is stored in the TES by circulating high temperature HTF through the HTF to PCM heat exchanger. The HTF which is at $393{ }^{\circ} \mathrm{C}$ transfers heat to the cold PCM $\left(292{ }^{\circ} \mathrm{C}\right)$ from cold storage tank, then hot PCM at $385{ }^{\circ} \mathrm{C}$ is stored in the hot storage tank. During peak demand hours or night when stored energy is neededthen direction of flow of HTF inHTF to PCM heat exchanger is reversed. During this heat is transferred to the HTF from hot PCM. Then high temperature HTF generates steam to run the power plant. The number of hours the TES can supply the energy depends on operating temperature range of system, amount of molten salt, thermal properties 
of molten salt and the energy requirement to fulfill the demand. By this way using PCM (molten salt) the offset of supply and demand is minimised.

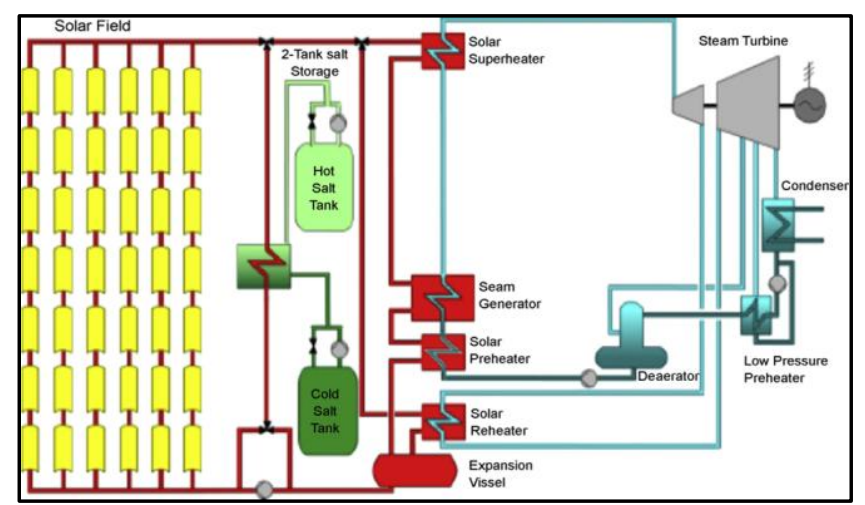

Fig-13:Schematic diagram of Concentrated Solar Power plant using parabolic through concentrators.

\section{CONCLUSIONS}

Solid-solid PCMs are good alternatives to solid-liquid PCMssince they do not have leakage problems, require less stringentcontainments and have better design flexibility. Solid-liquid PCMs are most studied and used PCMs. They are better options due to theirfavourable properties. Solutions and recommendations to the problems associated with PCMs give better insight in latent heat storage systems and will also help in the development of the new latent heat storage systems.

\section{Nomenclature}

\begin{tabular}{|l|l|}
\hline$Q$ & Amount of heat $(\mathrm{kJ})$. \\
\hline$M$ & Mass $(\mathrm{kg})$. \\
\hline$C_{p}$ & Specific heat of material $\left(\mathrm{kJ} / \mathrm{kg} .{ }^{\circ} \mathrm{C}\right)$. \\
\hline$C_{p s}$ & Specific heat of solid phase $\left(\mathrm{kJ} / \mathrm{kg} .{ }^{\circ} \mathrm{C}\right)$. \\
\hline$C_{p l}$ & Specific heat of liquid phase $\left(\mathrm{kJ} / \mathrm{kg} .{ }^{\circ} \mathrm{C}\right)$. \\
\hline$\Delta T$ & Temperature gradient $\left({ }^{\circ} \mathrm{C}\right)$. \\
\hline$T_{i}$ & Initial temperature $\left({ }^{\circ} \mathrm{C}\right)$. \\
\hline$T_{m}$ & Melting temperature $\left({ }^{\circ} \mathrm{C}\right)$. \\
\hline$T_{f}$ & Final temperature $\left({ }^{\circ} \mathrm{C}\right)$. \\
\hline$a_{m}$ & Fraction melted. \\
\hline$f_{r}$ & Fraction reacted. \\
\hline$H_{L}$ & Latent heat of fusion $(\mathrm{kJ} / \mathrm{kg})$. \\
\hline$H_{R}$ & Endothermic heat of reaction $(\mathrm{kJ} / \mathrm{kg})$. \\
\hline
\end{tabular}

\section{REFERENCES}

[1]. Sharma et al., Review on thermal energy storage with phase change materials and applications, Renewable and Sustainable Energy Review, Volume 13(2009), Issue 2, pp. 318-345.

[2]. F. Barnes \& J. Levine, Large Energy Storage Systems Handbook (2011), Chapter-7, Page no. 181-187, Boca Raton: CRC Press.

[3]. Sukhtame, S. P. \&Nayak, J. K. (2008). Solar Energy: Principles of Thermal Collection and Storage. New Delhi: Tata McGraw-Hill.

[4]. Bent S申rensen, Solar Energy storage (2015), Part-I,
Chapter-III, Page no. 32-35, London: Academic Press is an imprint of Elsevier.

[5]. Dutt S.D., Kitano H., Sagara K., Phase Change Materials for Low Temperature Solar Thermal Applications, Res. Rep. Fac. Eng. Mie Univ., Vol. 29 (2004), pp. 31-64.

[6]. M. M. Farid, et.al., A review on phase change energy storage: materials and applications. Energy Conversion and Management 45 (2004), pp.1597-1615.

[7]. H. Mehling\&L.F.Cabeza, Heat and Cold Storage with PCM (2008), Chapter-2, Page no. 11-52, Springer.

[8]. Goswami D.Y, Kreith F \&Kreider J.F, Principles of Solar Engineering- Second Edition (2000), Chapter-4, Page no.173-208, Taylor \& Francis Group,LLC.

[9]. Abhat, A. 1981. Low temperature latent heat thermal energy storage: Heat storage materials. Solar Energy.30(4), pp.313-332.

[10]. Zalba B, et.al., Review on thermal energy storage with phase change: materials, heat transfer analysis and applications. Applied Thermal Engineering Vol-23 (2003), pp. 251-283.

[11]. M. Kenisarin, K. Mahkamov, Solar energy storage using phase change materials, Renewable and Sustainable Energy Reviews 11 (2007) 1913-1965.

[12]. Product catalogue and information available on www.pcmproducts.net [cited on $10^{\text {th }}$ Oct 2015].

[13]. Anisur M.R. et al., Latent Heat Thermal Storages (LHTS) for Energy Sustainability. Energy sustainability through Green energy, Green Energy and Technology (2015), pp. 245-263.

[14]. Dhukan N. \& Bodke S., An improved PCM Heat Storage Tchnology using Metalfoam. IEEE(2010).

[15]. S. Kuravi et al., Review Thermal energy storage technologies and systems for concentrating solar power

[16]. Plants. Progress in Energy and Combustion Science 39 (2013), pp. 285-319.

\section{BIOGRAPHIES}

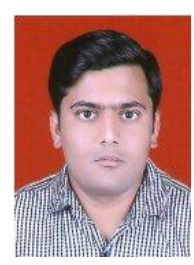

Kavendra A. Thakarereceived the B. Tech. degree in Marine Engineering from Maharashtra Academy of Naval Education and Training, Pune in 2010. He is now pursuing M.E. in Energy Engineering from K. J. Somaiya College of Engineering, Mumbai University. Email-ID:

kaven.thakare@gmail.com

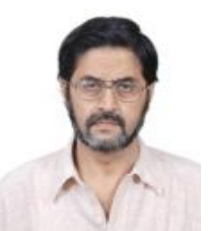

Dr. A.G. Bhavereceived the degree of Docteur-Ingenieur in ThermiqueIndustrielle, in the area of solar thermal energy, from Universite Paris XII in 1985 . He has worked in the renewable energy area since, and is working as a professor in the Mechanical Engineering Department of K. J. Somaiya College of Engineering, Mumbai since 2009. Email-ID: agbhave@gmail.com 